Approximately 600,000 people reside within the New Orleans bowl. The West Bank, located south of New Orleans and across the Mississippi River, has a population of about 500,000 people who also live within levee-protected bowls. Recent research reveals that a slow-moving Category 3 or stronger hurricane could cause levee overtopping and complete flooding of New Orleans, with the West Bank even more susceptible. Floodwaters would remain for weeks. The resultant mix of sewage, corpses, and chemicals would set the stage for massive disease outbreaks and prolonged chemical exposures. It is estimated that 300,000 persons would be trapped, 700,000 would be homeless, and thousands would perish. Of the communicable diseases, water-borne diseases will likely be the most common, followed by food-borne, vector-borne, and airborne-respiratory. Non-communicable conditions will include psychological, musculoskeletal, chronic diseases, physical, and toxic exposures. Vaccines that should be stockpiled in preparation for a flooded New Orleans include: influenza, pneumococcal pneumonia, measles, rubella, pertussis, tetanus, typhoid, and rabies.

Hurricane Ivan in 2004, a near miss for New Orleans, had the potential to flood the city. There is a need to implement a long-term coastal restoration plan to ensure the survival of New Orleans.

Keywords: coastal restoration plan; disease; flooding; hurricanes;

New Orleans; preparedness

Prehosp Disast Med 2005;20(2):s64-s65

\section{Earthquakes and Turkey}

M. Haberal; C. Ozcan; O. Basaran; H. Karakayali

Baskent University Faculty of Medicine, Turkey

Most earthquakes occur along three main belts in the world: (1) the Pacific Belt; (2) the MediterraneanHimalayan Belt; and (3) the Icelandic Belt. Turkey is located along the eastern part of the Mediterranean-Himalayan Belt. Turkey has five different risk zones with $96 \%$ of the surface area at risk for earthquake, and $98 \%$ of the population living within the risk zones.

On 17 August 1999, an earthquake measuring 7.4 on the Richter scale devastated the Marmara region, which is located within the North Anatolian Belt. Later that same year, on 12 November 1999, another earthquake, measuring 7.2 on the Richter scale, devastated Bolu and Düzce. These two earthquakes together affected seven cities, killed 18,223 people, and injured 48,901 . The human and material losses, and the rescue and relief activities carried out in the aftermath of these events, are summarized in this presentation. What is most important is that the people of Turkey have learned to live with earthquakes. Turkey now recognizes the importance that the necessary precautions are taken, and that social awareness concerning these earthquakes is extensive. While the nation has suffered immensely as a nation, the people also have learned from their experiences, and have upgraded the national emergency response system in order to be prepared for major destructive events in the future.

Keywords: disasters; earthquakes; preparedness; Turkey

Prehosp Disast Med 2005;20(2):s65

\section{Assessment of Medical Responses to Disasters at Kobe University Hospital}

A. Takahashi; T. Kawashima; N. Ishii; Y. Maeda; H. Nakao;

M. Terukina; N. Okada; T. Yoshida; M. Okashiro

Kobe University Graduate School of Medicine, Japan

Objective: In Japan, the concept of a disaster medical plan and its management has been in use since the Great Hanshin-Awaji Earthquake on 17 January 1995. Based on the lessons learned in coping with the earthquake, proactive efforts to improve the emergency management system have been made, such as introducing an information system for emergency medicine, designating more key disaster hospitals, and implementing disaster medicine education and trainings. However, even after the earthquake, delays in early response were identified in mass-casualty incidents like the Tokyo Sarin gas attack, the O-157 mass food poisoning, the Wakayama curry poisoning, the flood in Nagoya, and the mass-gathering disaster at the Akashi fireworks festival. These delays occurred because, under the current system, in the initial stage of a disaster, the assessment of medical response is made first in the local area, and then, when the amounts and types of damage are beyond the capacity of local emergency management, support from neighbor cities must be requested. Therefore, in order to shorten response times, it is necessary to assess the capacity for emergency medical responses in local areas during normal times, and to share the results in order to determine the capacity for deal with disasters and major accidents in the local area. In this presentation, an formula to estimate the emergency medical response (the capacity of receiving patients) in Kobe university hospital was analyzed as an example.

Methods: The records of a total of 5,213 emergency patients who were transported to Kobe University Hospital during January-December 2003 were examined. The required number of staff, equipment, and hours classified were determined for each disease. Based on the results, an approximation formulas was derived, which can indicate the capacity for receiving patients per $\mathrm{H}$ hour in the case of mass-casualties with serious injuries including heat injury, crush syndrome, and the need for blood purification.

Results: The approximation formula of capacity per $\mathrm{H}$ hour is suggested as follows: (1) for heat injury patients = highest common factor (Doctor/2, Respirator/1, Bed/1) x $\mathrm{H} / 2$; (2) for patients requiring blood purification = highest common factor (Doctor/2, Blood Purification Circuit/1, $\mathrm{Bed} / 1) \times \mathrm{H} / 2$; and for patients with external injuries = highest common factor (Doctor/2, Anesthetist/1, Respirator/1, Bed/1, Operation Room/1) x H/4.

Conclusions: An approximation formula that can be used for assessing the capacity of Kobe University Hospital for receiving patients was derived and tested. Using this approximation, the total emergency response and capacity for receiving patients in Kobe and Hyogo Prefecture can be determined. Also, this formula can be used to suggest the capacity for emergency responses of the whole nation. 
Furthermore, the application of the formula should contribute to the establishment of a management system for hospitals to receive injured victims on a regional basis. Keywords: assessment; blood purification; capacity; estimation; formula; heat; hospitals; injured victims; response

Prebosp Disast Med 2005;20(2):s65-s66

Impact of Two Terrorist Bombings on Two Hospitals in Istanbul, Turkey in November, 2003

U. Rodoplu, ${ }^{1}$ J.L. Arnold; ${ }^{2}$ R. Tokyay, ${ }^{3}$ T. Yücelt

1. Department of Emergency Medicine, Alsancak State Hospital, Izmir, Turkey

2. Department of Surgery, Section of Emergency Medicine, Yale University School of Medicine and the Yale-New Haven Center for Emergency and Terrorism Preparedness, New Haven, Connecticut USA

3. Department of Emergency Medicine, American Hospital, Istanbul, Turkey

4. Department of General Surgery, Taksim Education and Research State Hospital, Istanbul, Turkey

Objective: To estimate the impact of the terrorist bombings of the Hong Kong Shanghai Banking Corporation headquarters and the British consulate in Istanbul, Turkey on 20 November 2003 on two nearby hospitals in terms of epidemiological outcomes, resource utilization, and time course of emergency needs.

Methods: Data were abstracted from hospital records of injured survivors, who used the emergency departments (ED) at the Taksim Education and Research State Hospital (TERSH) and the American Hospital (AH) in Istanbul on 20 November 2003, to determine the totals and rates of mortality (early, late, and critical), injury, critical injury (injury severity score (ISS) $>15$ ), ED use, hospitalization, operative care, in-hospital over-triage, and the time intervals of ED arrival.

Results: The TERSH received 184 victims in the first hour after the initial blast, of which 88 (48\%) were brought by emergency medical services (EMS), 171 (93\%) had lacerations, $7(4 \%)$ had penetrating eye injuries, $28(15 \%)$ were hospitalized, $18(10 \%)$ received operative care, and seven (4\%) were critically injured. Three deaths occurred in critically injured survivors, including one early death in the operating room and two late deaths on days five and six. The $\mathrm{AH}$ received 16 victims, of which 14 (88\%) had lacerations, three (19\%) were hospitalized, two (13\%) received operative care, and one (6\%) was critically injured. An additional four victims were transferred to the $\mathrm{AH}$ from other hospitals, of which three were hospitalized, and none were critically injured. No early or late deaths occurred.

Conclusion: Mortality, injury, and hospitalization rates at both hospitals were consistent with previous reports of open-air, mass-casualty, terrorist bombings. The TERSH experienced an unprecedented demand for ED surge capacity in an open-air bombing.

Keywords: bombing; critical care; emergency department (ED); emergency management; emergency medical services (EMS); emergency medicine; hospital; injury; Istanbul; mass-casualty; terrorism; trauma; Turkey

Prehosp Disast Med 2005;20(2):s66
Lessons Learned Following the Mass-Casualty Terrorist Bombings in Istanbul, Turkey, November 2003 $\ddot{U}$. Rodoplu, ${ }^{1}$ J.L. Arnold; ${ }^{2}$ R. Tokyay, ${ }^{3}$ T. Yücel; ${ }^{4}$ G. Ersoy; ${ }^{5}$ S. Cetiner ${ }^{6}$

1. Alsancak State Hospital, Izmir, Turkey

2. Yale University School of Medicine, USA

3. American Hospital, Turkey

4. Taksim Education and Research State Hospital, Turkey

5. Dokuz Eylul University Medical Center, Turkey

6. Emergency Medicine Association of Turkey, Turkey

Objective: This study sought to describe the two masscasualty terrorist attacks that occurred in Istanbul, Turkey in November 2003 and the resulting prehospital emergency response.

Methods: A complex, retrospective, descriptive study was performed using open-source reports, interviews, direct measurements of street distances, and hospital records from the American Hospital (AH) and the Taksim Education and Research State Hospital (TERSH) in Istanbul.

Results: On 15 November 2003, improvised explosive devices (IEDs) in trucks were detonated outside the Beth Israel and Neve Shalom Synagogues, killing 30 persons and injuring an estimated 300 . At least 50 ambulances were dispatched to the scenes. Victims were distributed to at least 23 medical facilities. The $\mathrm{AH}$, a private hospital located six kilometers from both synagogues, received 69 injured survivors, of which $86 \%$ had secondary blast injuries and $13 \%$ were admitted to the hospital. The TERSH, a government hospital located one kilometer from both synagogues, received 48 injured survivors. On 20 November, IEDs in trucks were detonated outside the Hong Kong Shanghai Banking Corporation (HSBC) headquarters and the British Consulate (BC), killing 33 and injuring an estimated 450. At least 50 ambulances were dispatched to the scenes. Victims presented to at least 24 medical facilities. The TERSH, located 18 kilometers from the HSBC site and two kilometers from the BC site, received 184 injured survivors, of which $93 \%$ had secondary blast injuries, and $15 \%$ were hospitalized. The $\mathrm{AH}$, located nine kilometers from the HSBC site and six kilometers from the BC site, received 16 victims.

Conclusion: The twin suicide truck bombings on 15 and 20 November 2003 were the two largest terrorist attacks in modern Turkish history, collectively killing 63 persons and injuring an estimated 750 . The vast majority of victims had secondary blast injuries that were relatively minor. Victims were distributed unequally to medical facilities on both dates.

Keywords: bombing; emergency management; emergency medical services (EMS); emergency medicine; injury; maldistribution; terrorism; trauma; Turkey

Prebosp Disast Med 2005;20(2):s66 